\title{
Comparative Transcriptome Reveals Benzenoid Biosynthesis Regulation as Inducer of Floral Scent in the Woody Plant Prunus mume
}

\author{
Kai Zhao ${ }^{\dagger}$, Weiru Yang ${ }^{\dagger}$, Yuzhen Zhou, Jie Zhang, Yushu Li, Sagheer Ahmad and \\ Qixiang Zhang *
}

Beijing Key Laboratory of Ornamental Plants Germplasm Innovation and Molecular Breeding, National Engineering Research Center for Floriculture, Beijing Laboratory of Urban and Rural Ecological Environment, Key Laboratory of Genetics and Breeding in Forest Trees and Ornamental Plants of Ministry of Education, School of Landscape Architecture, Beijing Forestry University, Beijing, China

OPEN ACCESS

Edited by:

Maoteng $\mathrm{Li}$

Huazhong University of Science and

Technology, China

Reviewed by:

Hauke Busch

University of Lübeck, Germany

Treenut Saithong,

King Mongkut's University of

Technology Thonburi, Thailand

*Correspondence:

Qixiang Zhang

zqxbjfu@126.com

${ }^{\dagger}$ These authors have contributed equally to this work.

Specialty section:

This article was submitted to Crop Science and Horticulture, a section of the journal

Frontiers in Plant Science

Received: 04 November 2016 Accepted: 22 February 2017 Published: 10 March 2017

Citation:

Zhao K, Yang W, Zhou Y, Zhang J, LiY, Ahmad S and Zhang Q (2017) Comparative Transcriptome Reveals Benzenoid Biosynthesis Regulation as Inducer of Floral Scent in the Woody

Plant Prunus mume.

Front. Plant Sci. 8:319.

doi: 10.3389/fpls.2017.00319
Mei (Prunus mume) is a peculiar woody ornamental plant famous for its inviting fragrance in winter. However, in this valuable plant, the mechanism behind floral volatile development remains poorly defined. Therefore, to explore the floral scent formation, a comparative transcriptome was conducted in order to identify the global transcripts specifying flower buds and blooming flowers of $P$. mume. Differentially expressed genes were identified between the two different stages showing great discrepancy in floral volatile production. Moreover, according to the expression specificity among the organs (stem, root, fruit, leaf), we summarized one gene cluster regulating the benzenoid floral scent. Significant gene changes were observed in accordance with the formation of benzenoid, thus pointing the pivotal roles of genes as well as cytochrome-P450s and short chain dehydrogenases in the benzenoid biosynthetic process. Further, transcription factors like EMISSION OF BENZENOID I and ODORANT I performed the same expression pattern suggesting key roles in the management of the downstream genes. Taken together, these data provide potential novel anchors for the benzenoid pathway, and the insight for the floral scent induction and regulation mechanism in woody plants.

Keywords: Mei, floral scent, transcriptome, benzenoid biosynthesis, transcription factors

\section{INTRODUCTION}

Presence of volatiles in the flowers has been a special attraction for humans since antiquity and with time this appeal has permeated several aspects of man's life. As a matter of fact, they have become integral constituents of cosmetics, perfumes, medicinal products, and flavorings. However, they are primarily involved in maintaining the ecological bridging of flowers to that of diverse range of visitors (florivores, pollinators, pathogens), thereby playing a significant role in reproductive success and evolutionary variability in plants. The intricate biochemical pathways behind their synthesis are driven by both internal and external factors, thus enabling the controlled spatial and temporal emission of floral volatiles (Muhlemann et al., 2014). Persuasive floral scent by these volatiles is the most demanding trait in ornamental plants as an esthetic preference for 
consumers and an attraction for pollinators as well (Pichersky and Dudareva, 2007; Raguso, 2008). Complex lipophilic molecules with low-molecular weight determine the quality of floral scent (Dudareva and Pichersky, 2008) and to date, more than 1,700 floral scent related compounds have been recognized which are synthesized through terpenoid, phenylpropanoid/benzenoid, and fatty acid biosynthetic pathways (Knudsen et al., 2006; Muhlemann et al., 2014).

Mei (Prunus mume Sieb. et Zucc.) is an important fruit tree in China and other East Asian countries for its economic value (Chen, 1996). It has been domesticated with favorite ornamental characteristics, incorporating colorful corollas, varying types of branches, and particularly inviting fragrance (Sun et al., 2013; Xu et al., 2014; Zhang et al., 2015). However, little is known about the molecular mechanisms that control flower aroma formation in this fantastic species. Mei flowers produce a strong aroma of benzenoids, and benzyl acetate protrudes from the dominant compounds. This endows $P$. mume with an excellent advantage from the most interspecific hybrids and other species of Prunus.

Floral scent emission is often restricted to particular flower tissues which is believed to be regulated at the level of scent biosynthetic gene expression and enzyme activity. The biosynthesis of phenylpropanoid/benzenoid compounds has been described synoptically with the discovery of core enzymes and the exhaustive $\beta$-oxidative pathway in petunia (Qualley et al., 2012). In different species, the floral scent of benzenoids tends to be various owing to the modification in the final step such as methylation, hydroxylation, and acetylation (Boatright et al., 2004; Klempien et al., 2012). Benzyl acetate was reported to be synthesized from benzyl alcohol in Clarkia (Nam et al., 1999). However, the formation of part precursors like benzaldehyde remains uncharted.

Presently, RNA sequencing is an important application to analyze the mechanism controlling unique plant feature formation at transcriptional levels (Bar-Akiva et al., 2010; Onda et al., 2015). It helps researchers find novel gene functions and set their interaction among huge data. Though the lack of reference genome is one of the limitations for many scented plants, such as ylang ylang, syringa oblate, and winter sweet, RNA-seq profiling still provides an instrument to measure large scale transcript changes in normalized samples and allows the inter comparison to recognize core regulatory genes (Liu et al., 2014; Jin et al., 2015; Zheng et al., 2015). Especially for the benzenoid type scented plants, the differentially expressing genes depict an outline for the biosynthesis of benzenoids in each species. Meanwhile, several transcriptional factors (TF) are also mentioned in the regulation of benzenoid biosynthesis of petunia flowers. ODORANT1 is the first identified TF to guide the flux in shikimate pathway, and EMISSION OF BENZENOIDS I and II positively regulate the phenylpropanoid/ benzenoid pathway (Verdonk et al., 2005; Spitzer-Rimon et al., 2010). Recently, the interplay of these three MYB TFs has been demonstrated (Van Moerkercke et al., 2011; Fenske et al., 2015).

Since the complete genome sequencing in 2012, scent formation has been regarded as an important character to study in P. mume (Zhang et al., 2012). RNA-seq studies demonstrate vigorous strength to identify the putative genes specifying the biosynthesis of benzenoid precursors and regulatory mechanism in this volatile species. In this study, a comparative transcriptome of Mei flower was constructed by two transcription datasets for developed flower buds and blooming flowers. Differentially expressed genes (DEGs) were first extracted and narrowed by associating transcriptomes of different organs (from leaf, fruit, stem, and root). Specially expressed genes encoding transcription factors and enzymes like short-chain dehydrogenases/reductases (SDRs) and cytochrome P450s were highlighted. These datasets could be applied as significant resources to supplement benzenoid metabolic processes and regulation mechanism. Furthermore, they would furnish vital clues to uncover other biological mechanisms in nearby species and scent-related plants.

\section{MATERIALS AND METHODS}

\section{Plant Materials Collection and RNA Extraction}

Plant materials were obtained from P. mume "Sanlun Yudie" at the Beijing Forestry University, China $\left(116.3^{\circ} \mathrm{E}, 40.0^{\circ} \mathrm{N}\right)$. The samples were collected at fixed daytime $(10: 00 \mathrm{am})$ to differentiate the aroma changing phase including flower buds at different expanding stages (well-developed, S1-S3) and blooming flowers (S4-S6) with typical Mei scent as shown in Figure 1 (Chen, 1996; Wang et al., 2014). Immediately after collection, samples were frozen in liquid nitrogen, and stored at $-80^{\circ} \mathrm{C}$. Total RNAs of two stages (S2 and S4) were extracted applying RNAisomate RNA Easy spin Isolation System, and were assessed using NanoDrop ND2000 (Liu et al., 2015). A260/A280 was $1.8 \sim 2.2,28 \mathrm{~S} / 18 \mathrm{~S}>1.0$, RNA concentration $\geq 400 \mathrm{ng} / \mu \mathrm{L}$.

\section{Illumina Sequencing and Reads Mapping}

To reveal the difference between non-scent buds and scented blooming flowers, equivalent quantities of RNA were isolated from same stages from three trees, each individual contained 5-10 flowers. Then sample from same stages were mixed to average the difference between individuals. Total of $10 \mu \mathrm{g}$ RNA samples were selected to construct comparative sequencing pools of S2 and S4 stage, respectively. Preparation of the cDNA library was applied in detail to construct two libraries, Bud and Flower, for comparative transcriptome sequencing. Then, sequencing was performed by Illumina $\mathrm{HiSeq}^{\mathrm{TM}} 2000$ platform (BGI, Shenzhen, China) and 100 bp paired-end format raw reads were generated according to the manufacturer's instructions by base calling (Illumina Inc. San Diego, CA). After filtering raw reads (adaptor sequences, empty reads, reads with unknown nucleotides larger than $5 \%$ and ambiguous $\mathrm{N}$ ), we employed clean reads for mapping the P. mume genome v.1.0 (http://prunusmumegenome.bjfu.edu.cn/). Mapping of the clean reads was carried out with SOAP2 under default parameters allowing 5 mismatches at the most (Hurgobin, 2016). The reference gene was defined as an expression gene, if at least one clean read showed unique match. P-fam database was attained from the reference annotation of the P. mume genome. This comparative transcriptome was deposited in the Genome sequence archive (GSA). The accession numbers were PRJCA000274. And the associated datasets involving different 


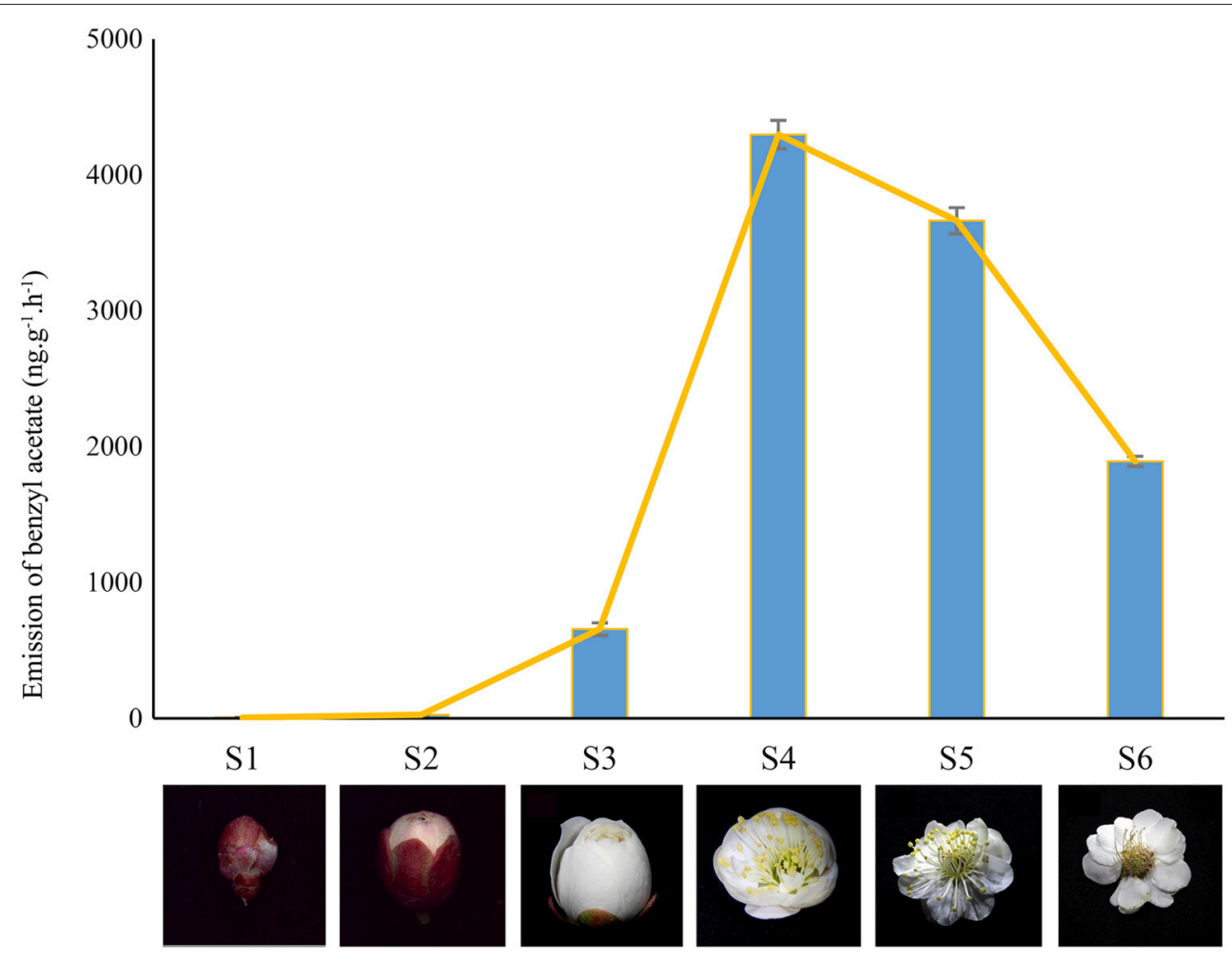

FIGURE 1 | Different developing stages from $P$. mume (S1-S3) Developed bud; (S4) Squaring flower; (S5) fully blooming stage; (S6) fading stage. The flowers in stages of S2 and S4 were used to pool cDNA libraries for Illumina sequencing.

organs (leaf, root, stem, fruit) were acquired from NCBISequence Read Archive (SRA) with accession numbers of SRP014885.

\section{DEG Selection, Expression Patterns Analysis, and Function Annotion}

Differentially expressed genes were primarily detected by the software of edgeR. Then, the fold change [absolute value of $\log _{2}$ (fold change) $>1$ ] and FDR $\leq 0.05$ was used as the threshold to determine significant differences in gene expression (Audic and Claverie, 1997; Mariani et al., 2003). Transcripts per million (TPM) was used to provide normalized values of gene expression that enabled transcript comparisons between samples While the variations in gene length and the size of library matters ( $\mathrm{Li}$ and Dewey, 2011).

For the DGEs, latest Gene Ontology (GO) annotations were obtained using Blast2GO v.2.3.5 with the default parameters. GO terms of DEGs were significantly enriched by gene set enrichment analysis (GSEA) with the correct $P<0.05$.

HMMER 3.0 software with a threshold $E$-value of $10^{-5}$ was applied to search against the databases (Finn et al., 2015). Transcription factors were labeled under iTAK (http://bioinfo.bti.cornell.edu/cgi-bin/itak/index.cgi) based on conserved domains of genes (Zheng et al., 2016). For the pathway exhibition, MapMan analysis were performed by calculating the fold change of the genes (Klie and Nikoloski, 2012; Ramsak et al., 2014; Chandran et al., 2016).
Sequences of DGEs were uploaded and annotated by Mercator (http://www.plabipd.de/portal/mercator-sequence-annotation). Final display and automatic application of the Wilcoxon rank sum test were conducted by MapMan version 3.6.0.

Subsequently, the differentially expressed TFs were picked out from DEGs. STEM (Short Time series Expression Miner) software (http://www.cs.cmu.edu/ jernst/stem/) was used to gather the specially expressed DEGs and distinguished the temporal expression profiles (Ernst and Bar-Joseph, 2006).

\section{qRT-PCR Verification}

Experimental method for quantitative reverse transcription-PCR was applied as formerly described (Zhou et al., 2016). The primers for qRT-PCR were designed with Oligo8 software (Supplementary Table 1). Total RNA was extracted from samples using Trizol reagent (Invitrogen, USA) following the manufacturer's instructions. RNA was treated with RNase-free DNase (Promega, USA) to remove residual genomic DNA. Firststrand cDNA was synthesized from $2 \mu \mathrm{g}$ total RNA using a TIANScript First Strand cDNA Synthesis Kit (Tiangen, China) according to manufacturer's instructions. Realtime RT-PCR was conducted using the PikoReal real-time PCR system (Thermo Fisher Scientific, Germany). Reactions were carried out in a 20 $\mu \mathrm{l}$ volume containing $0.5 \mu \mathrm{l} \mathrm{cDNA}, 400 \mathrm{nM}$ each primer, and 10 $\mu l$ SYBR Premix Ex Taq II (Takara, China) with the following conditions: $30 \mathrm{~s}$ at $95^{\circ} \mathrm{C}, 40$ cycles of $5 \mathrm{~s}$ at $95^{\circ} \mathrm{C}$, and $30 \mathrm{~s}$ at $60^{\circ} \mathrm{C}$. Melting curve analysis was conducted to test the specificity of 
TABLE 1 | Statistics of the reads obtained and their mapping information on the genomes of Mei flower.

\begin{tabular}{|c|c|c|c|c|c|c|c|c|}
\hline $\begin{array}{l}\text { Library } \\
\text { name }\end{array}$ & $\begin{array}{l}\text { Total } \\
\text { reads }\end{array}$ & $\begin{array}{c}\text { Genome } \\
\text { map rate (\%) }\end{array}$ & $\begin{array}{c}\text { Gene map } \\
\text { rate }(\%)\end{array}$ & $\begin{array}{c}\text { Expressed } \\
\text { Gene }\end{array}$ & $\begin{array}{c}\text { Perfect } \\
\text { match (\%) }\end{array}$ & $\begin{array}{c}\text { Unique } \\
\text { match (\%) }\end{array}$ & $\begin{array}{l}\text { Unmapped } \\
\text { reads (\%) }\end{array}$ & $\begin{array}{l}\text { Max } \\
\text { TPM }\end{array}$ \\
\hline Bud & $24,961,904$ & 76.81 & 64.48 & 21,050 & 48.28 & 73.65 & 23.19 & 139,727 \\
\hline Flower & $24,885,518$ & 61.43 & 63.10 & 20,890 & 37.66 & 58.92 & 38.57 & 352,186 \\
\hline
\end{tabular}

TABLE 2 | Expression of eight selected housekeeping genes.

\begin{tabular}{|c|c|c|c|c|c|c|c|c|c|}
\hline \multirow[t]{2}{*}{ Gene name } & \multirow[t]{2}{*}{ Conserved domain } & \multirow[t]{2}{*}{ Locus tag } & \multirow[t]{2}{*}{ Query } & \multirow[t]{2}{*}{ Length } & \multicolumn{2}{|c|}{ Coverage } & \multicolumn{2}{|c|}{ TPM } & \multirow[t]{2}{*}{$\log _{2} F D$} \\
\hline & & & & & Bud & Flower & Bud & Flower & \\
\hline Actin2/7 & actin & Pm005252 & AT5G09810 & 906 & 98.90 & 98.90 & 155 & 193 & 0.31 \\
\hline PP2A-1 & ProteinPhosphatase 2A & Pm029033 & AT1G13320 & 1764 & 99.72 & 99.89 & 432 & 546 & 0.33 \\
\hline PP2A-2 & Protein phosphatase 2A & Pm006362 & AT1G59830 & 921 & 99.78 & 99.78 & 627 & 1359 & 1.11 \\
\hline SAND & SAND family protein & Pm001035 & AT2G28390 & 1833 & 99.18 & 98.87 & 126 & 225 & 0.83 \\
\hline TEF2 & Translation enlongation factor 2 & Pm011035 & AT1G56070 & 2532 & 99.92 & 99.92 & 2690 & 2983 & 0.14 \\
\hline TUA & Alpha Tubulin-5 & Pm000088 & AT5G19780 & 1353 & 99.19 & 99.04 & 1760 & 2797 & 0.66 \\
\hline UBQ & Ubiquitin & Pm009747 & AT4G02890 & 1599 & 100.06 & 100.06 & 2300 & 7639 & 1.73 \\
\hline UBC & Ubiquitin conjugating enzyme E2 & Pm024097 & AT5G53300 & 447 & 98.66 & 99.33 & 3849 & 8452 & 1.13 \\
\hline
\end{tabular}

each primer pair. All qRT-PCR experiments were implemented with three biological replicates, and each replicate was analyzed in triplicate. The relative expression levels were calculated using the $2^{-\Delta \Delta \mathrm{Ct}}$ method, with the protein phosphatase 2A (PP2A) gene of $P$. mume as the reference gene (Wang et al., 2014).

\section{RESULTS}

\section{Datasets Evaluation}

In the aggregate, two sample pools yielded 24.9 and 24.8 million reads corresponding to over 2.2 billion basepairs each sample (Table 1). Valid quality scores of the reads were received with balanced nucleotide distribution. We achieved 76.81 and $61.43 \%$ genome map ratios in bud and flower, respectively. The detailed quality scores across all bases and the mapping information for both pools were separately listed (Supplementary Figure 1). A total of 22,429 expressed genes were gathered in both libraries and 19,511 expressed genes emerged in both pools. As a whole, TPM got max values of 139,727 and 352,186 in both stages, respectively. There were 90 genes with TPMs above 5,000 in the bud, while 237 in the flowers.

Except the heads and tails, reads were distributed uniformly on the gene body, indicating better sequencing randomness which availed the next analysis. To estimate gene expression, eight housekeeping genes covering Actin and PP2A were selected (Wang et al., 2014). Based on pairwise comparisons of the two stages, none of these reference genes could give obvious differential expression, with $\log _{2}$ (fold change) ranging from 0.14 for Translation enlongation factor 2 to 1.73 for Ubiquitin. As for the common reference genes of P. mume, the TPM of Proteinphosphatase2A-1 stayed around 432-546. The expressions of housekeeping genes remaining stable between different pools illustrated accuracy of this transcriptome, and met the requirements for further analysis (Table 2).

\section{Screening of DEGS Associated with Scent Emission}

In accompany with the flower bud development, benzyl acetate in Mei flower presented vast accumulation, from S2 to S4, then decreased at S5-S6. To identify the DEGs in both developmental stages, we calculated the number of clean tags for each gene, and the DEGs between the two stages were detected according to the described method. In the library of Flower compared to Bud, a total of 7,813 DEGs were exposed, containing 2,664 upregulated and 5,149 down-regulated genes (Figure 2). Most of these genes declined in the blooming flower suggesting that there were more complex activities in buds (Supplementary Figure 2, Supplementary Tables 3,4). Furthermore, 401 and 356 genes expressed uniquely in flower and bud, respectively, and 7,056 genes, about $90.31 \%$ of all the DEGs, appeared in both libraries, but at different levels.

The gene expressions of five organs (bud, fruit, leaf, root, and stem) were manifested from the former transcriptome datasets under the same platform. In combination with the results of different organs transcriptome, all DEGs were classified by STEM cluster analysis. The cluster analysis of DEGs disclosed 64 expression profiles, with 11 remarkable profiles (Figure 3 ). The genes specially expressed in the bud and flower displayed potential correlation with the emission of volatile compounds. Cluster $46, P$-value $6.5 \mathrm{E}-11$, gathered this pattern profile $(0,1,-$ $1,-1,-1,-1)$ with 681 genes representing that these genes started expressing from buds, gained peak expression in the flower and showed low expression in other organs.

\section{Gene Annotation and Classifications for the DEGS}

Among 7,813 DEGs, approximately 5,089 genes could be annotated in GO database by sequence homologies, while 6,878 


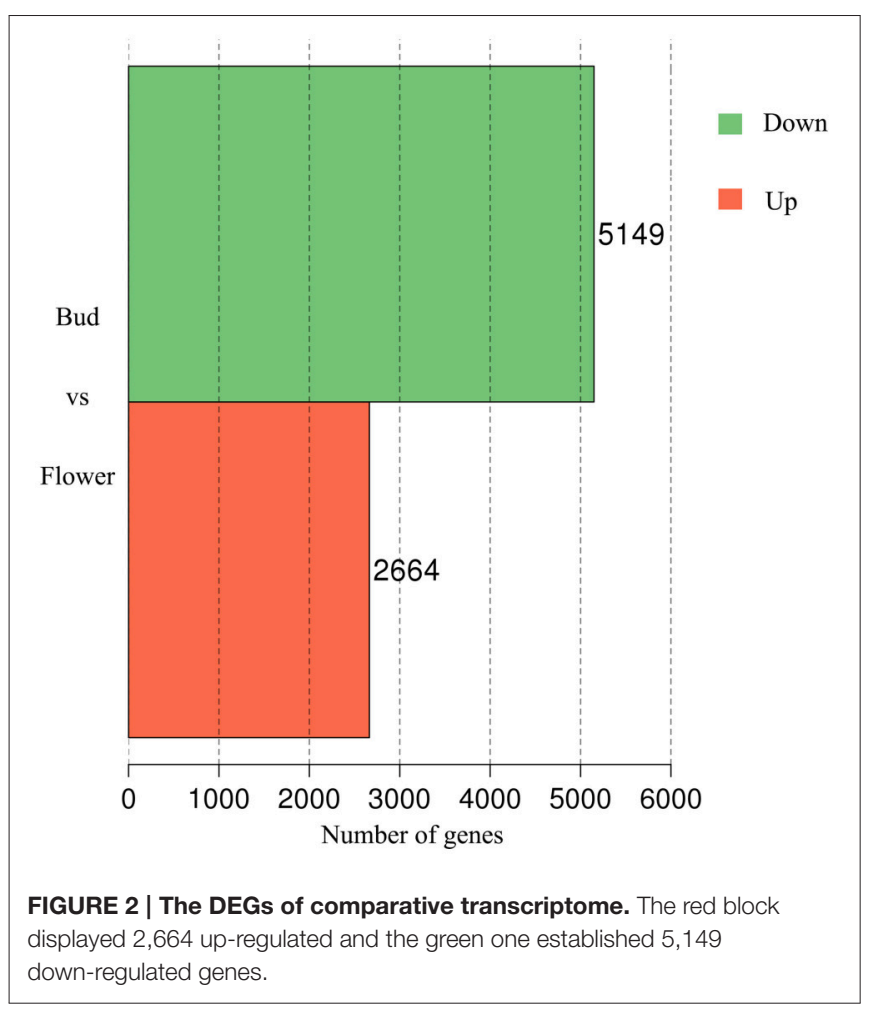

genes got hit in Arabidopsis thaliana (Supplementary Figure 3) with an overview fabricated by MapMan (Figure 4). As shown in the metabolism overview map, most DEGs lay on the subareas of second metabolism, lipids metabolism, and cell wall metabolism. Between the two stages from bud to blooming, the cells of Mei flower seemed to accomplish the division and 159 genes out of 417 still function in the development pathway of cellular response. The changes of cell function concentrated on the protein degradation and posttranslational modification. And proteins in many large enzyme families broke like Cytochrome P450, UDP glycosyltransferases, and peroxidases. The secondary metabolic processes were expounded in detail (Figure 5), and enriched in pathways like phenlypropanoids, lignin, and lignans, dramatically.

To differentiate the functions of the separated genes, GO enrichment analysis was performed (Supplementary Table 5), and the predominant GO categories are presented (Figure 6). In the categories, 5,089 annotated DEGs were divided into 41 functional GO subcategories within the three main ontologies (biological processes, cellular component, and molecular function). In the biological process ontology, metabolic processes and cellular processes possessed the top two represented GO categories, with 2,301 and 1,814 genes, respectively. In addition, 1,485 genes were annotated to single-organism process. GO categories "Cell" and "Cell part" ranked the top two in the cellular component ontology, with both 829 genes. And "membrance" and "organelle" possessed 577 and 441 respectively. These genes were associated with cell cycle control, cell division, and chromosome partitioning. In the molecular function ontology, a mass of genes were annotated to the categories of Binding and Catalytic activity (3,248 and 2,622). Two hundred forty-six genes were annotated to transporter activity. The GO annotations of these genes might aid in the identification of the molecular mechanisms of floral scent production and emission.

\section{Analysis of Proposed Genes Related to Known Benzenoid Biosynthesis}

To highlight the pathway of benzenoid biosynthesis in P. mume, and recognize the functions of committed genes in this pathway, the pivotal encoding enzymes were sought by the phmmer search from HMMER 3.0.

The biosynthesis of benzenoids in plant usually starts from shikimate and through arogenate pathways to form phelalanine, which crosses the boundary between primary and second metabolism (Figure 7). The seven reactions catalyzed by six enzymes formed the shikimate pathway, and transforms phosphoenolpyruvate (PEP) with erythrose 4phosphate (E4P) to chorismate (Tzin and Galili, 2010). Fourteen shikimate pathway genes were spotted in the $P$. mume genome, possessing four 3-deoxy-7-phosphoheptulonate synthase (PmDAHPS), one 3-dehydroquinate synthase (PmDHQS), three dehydroquinate dehydratase/shikimate dehydrogenase ( $P m D H D / S H D)$, three shikimate kinase ( $P m S K)$, two 3-phospho shikimate 1-carboxyvinyltransferase genes (PmEPSPS), and one chorismate synthase gene $(P m C S)$. For these genes, two out of four PmDAHPSs displayed enormous expression difference. The TPM of PmDAHPS1 declined from 5,646 to 788, and that of PmDAHPS2 rose dramatically from 1,508 to 50,480. As for other genes along the pathway, the expression kept low or declined. The TPM levels of these genes at both stages were declared in detail (Supplementary Table 2).

After the formation of chorismate, phenylalanine was synthesized under the catalysis of three chorismate mutases $(P m C M s), 17$ prephenate aminotransferase (PmPAT) genes, and four arogenate dehydratases (PmADTs) in P. mume. In four ADT genes, only PmADT1and PmADT2 were ascending significantly at the flower squaring process (Figure 7). And the peak TPM of PmADT2, around 13,686, was almost 2-fold more than that of PmADT1.

$P A L$, which is recognized as beginner/precursor of benzenoid biosynthesis, deaminates phenylalanine to cinnamic acid (Zhang and Liu, 2015). Three PmPALs existed in the P. mume genome and two of them were significantly regulated with TPMs 35,788 and 3,648 in the blooming flower. Then, phelalanine (C3 type) was split toward different pathway to synthesize phenylpropanoid-related compounds (C2 type) or benzenoids (C1 type). In the flower of rose, phenylalanine was converted into phenethyl alcohol by the way of phenylacetaldehyde, under two enzymes, PAAS and PAR. In P. mume, 6 PmPAASs were found, and only one got the max TPM 4,553 and 3.51-fold change in squaring stage. When $P A R$ was used as query to find the homologous genes in $P$. mume, 32 candidate PmPARs heaved out and two of them stated high transcription in blooming stage.

The CoA-dependent $\beta$-oxidative pathway, which catalyzes trans-cinnamic acidinto benzoic acid (BA) in petunia flowers, implicates three enzymes. We used the characterized petunia genes as baits to search of $P$. mume genome, 37 Cinnamate:CoA 


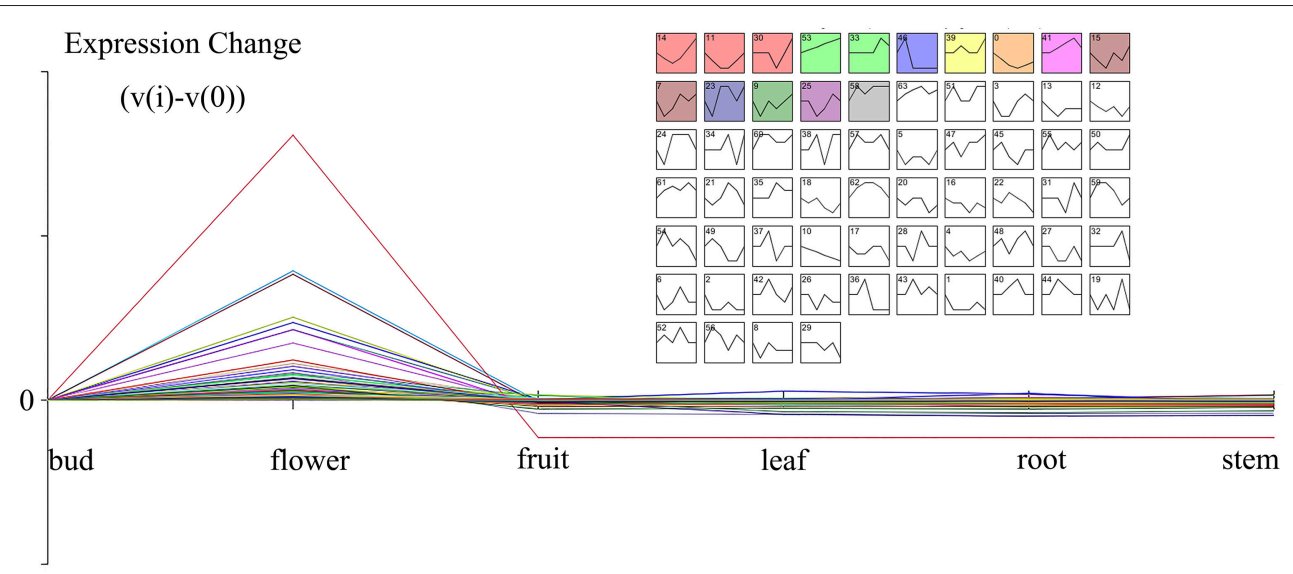

FIGURE 3 | The enlarged cluster 46 (Blue block, $p$-value 6.5E-11) showed the scent related genes with a pattern of flower organ specificity. Clusters ordered based on number of genes and profiles ordered by significance.

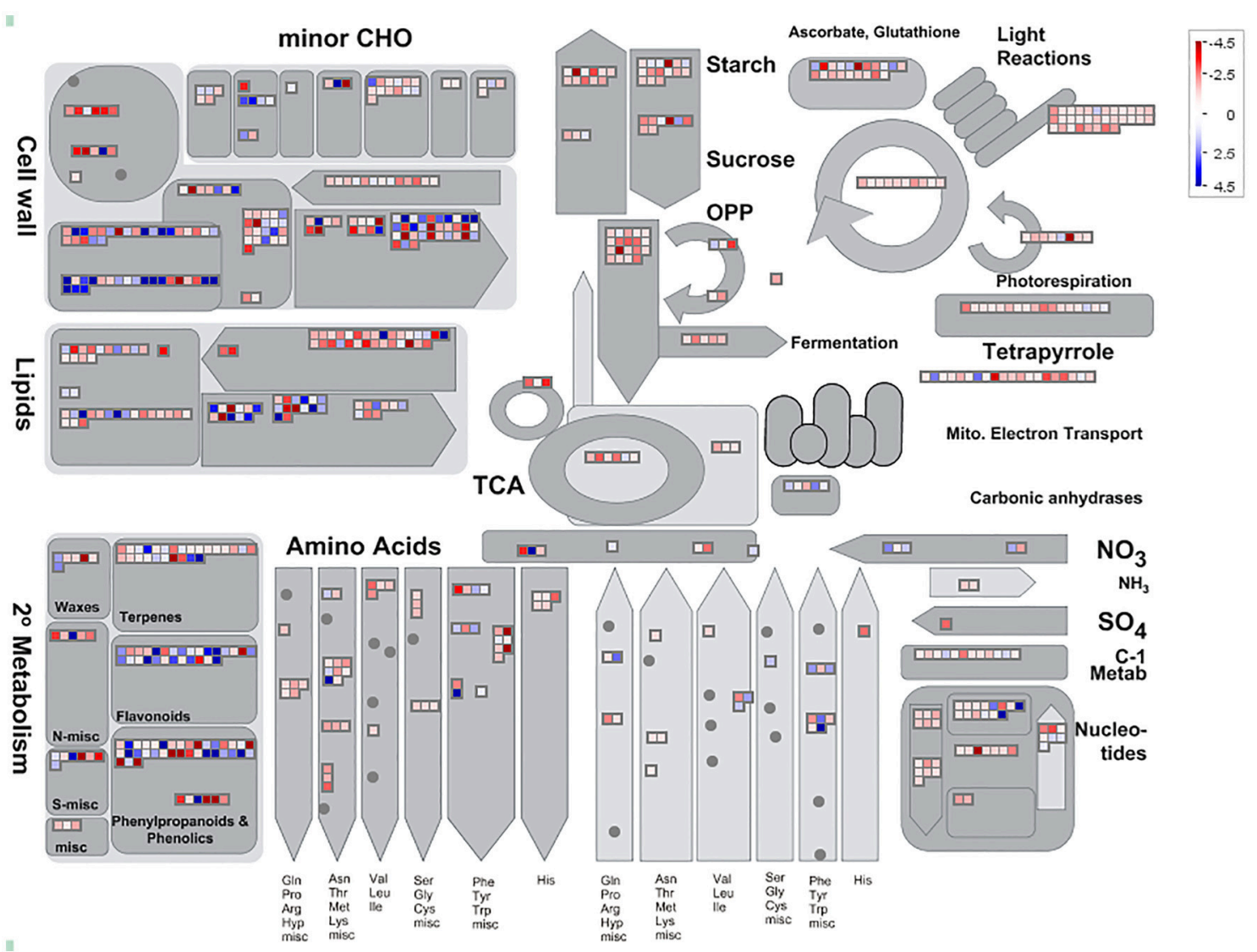

FIGURE 4 | Analysis of candidate genes using MapMan. Metabolism Overview revealed candidate genes assigned to 16 processes: cell wall metabolism, minor carbohydrate metabolism, starch metabolism, sugar metabolism, photosynthesis including light reactions, tetrapyrrole, Calvin Cycle, and photorespiration, glycolysis, metabolism, TCA Cycle, oxidative pentose phosphate pathway, mitochondrial electron transport, amino acid biosynthesis, nucleotide metabolism, lipid metabolism, and secondary metabolism. The blue diamonds mean up-regulated, otherwise in the red.

ligase/acylactivating enzyme ( $P m C N L / A A E)$, 14 cinnamoyl-CoA hydratase dehydrogenase $(P m C H D)$, and four 3-ketoacyl CoA thiolase $(P m K A T)$ were found. The expression pattern of two
PmCNL genes showed highly positive correlation with the emission of volatile benzenoids. PmCNL1 possessed an almost 6fold change from 113 to 10,117, and PmCNL6 kept high TPM 


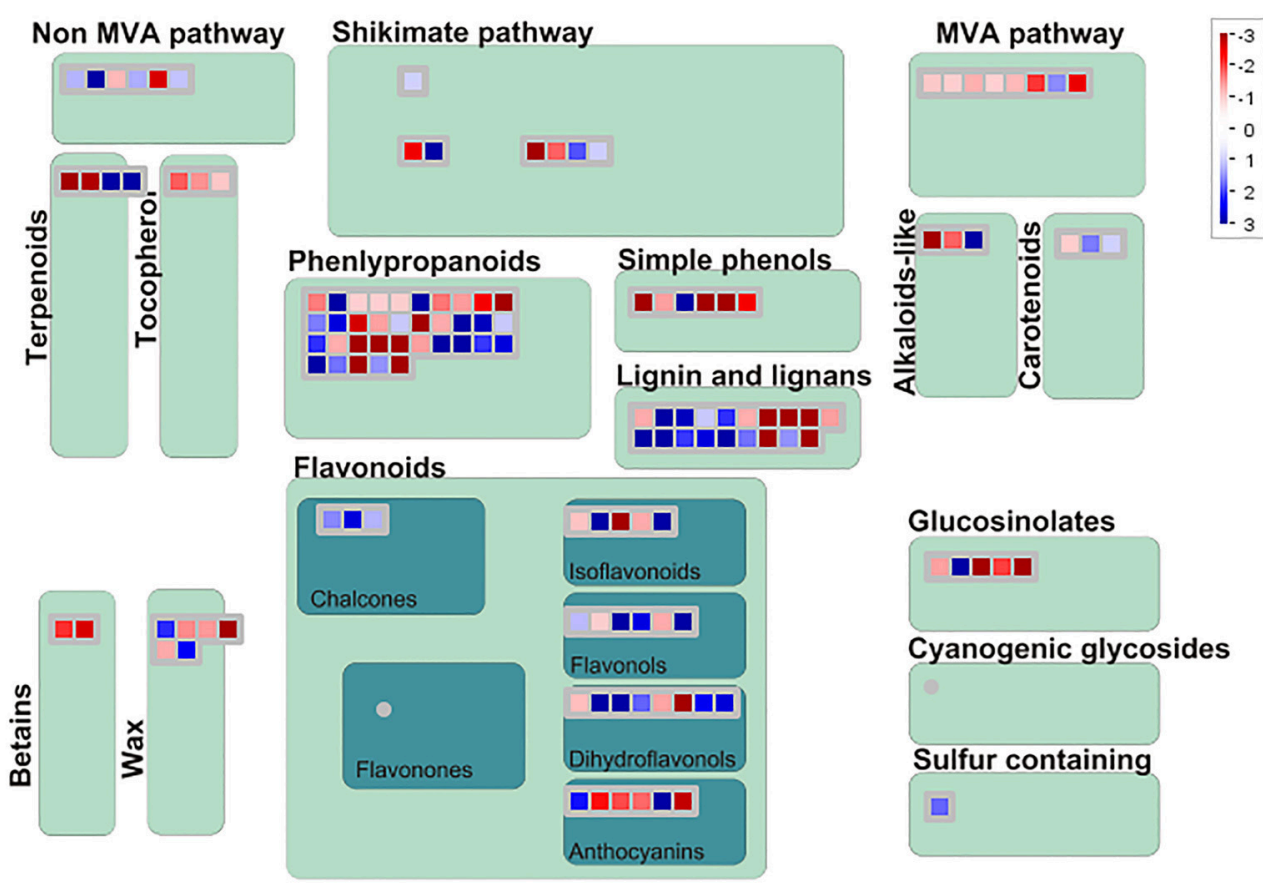

FIGURE 5 | Display of secondary metabolism by Mapman. DEGs focus on the pathway of phenlypropanoids, Lignin and lignans, shikimate etc. The blue diamonds mean up-regulated, otherwise in the red.

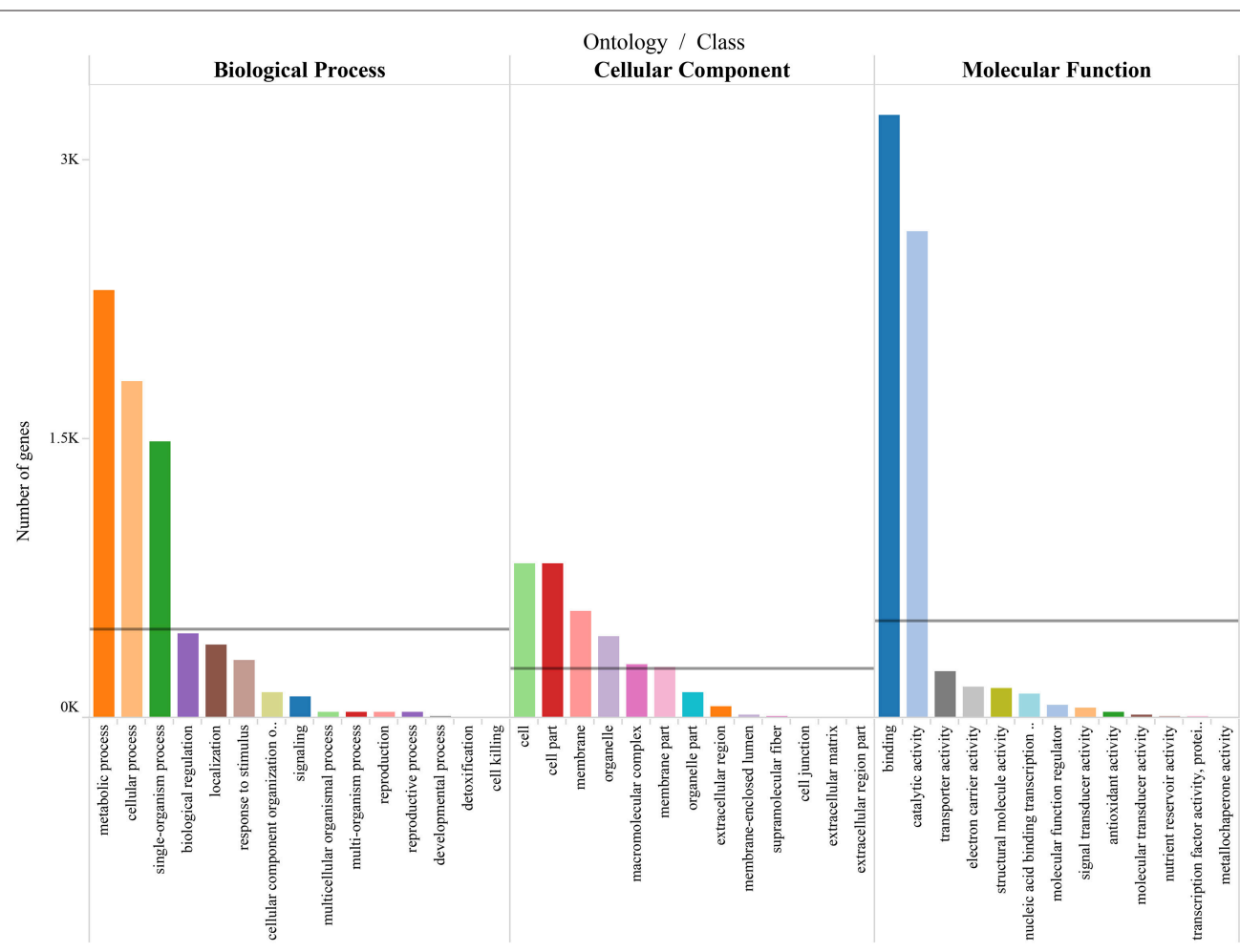

FIGURE 6 | Gene ontology categories of P.mume DEGs. The results are summarized in mainly three categories: biological process, cellular component and molecular function. The lines reveal the averages of genes in each category. 


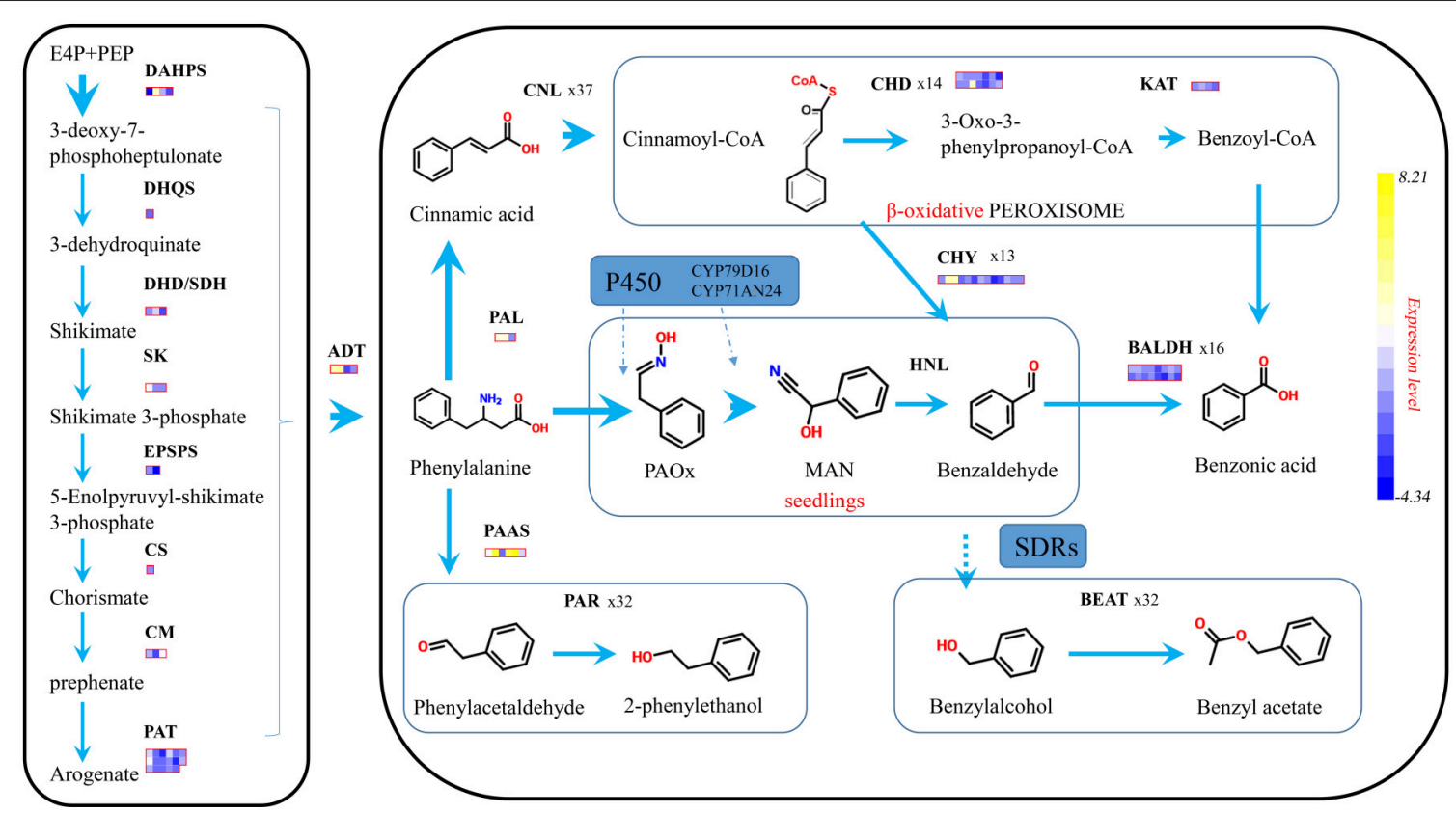

FIGURE 7 | Proposed schematic representation of phenylpropanoid/ benzenoid biosynthetic pathway. Phenylpropanoid/ benzenoids are derived from phenylalanine, which itself is synthesized via the shikimate biosynthetic pathways. Larger arrows indicate there exist genes with strong expression level above 5 thousand of TPM. Each block means a fold change for a single gene.

from 5,069 to 12,970. For PmCHDs and PmKATs, the expression from bud to blooming stage showed insignificant change.

Benzaldehyde dehydrogenase $(B A L D)$ was reported to account for the oxidation of benzaldehyde into benzoic acid in non- $\beta$-oxidative pathway. In $P$. mume, 16 PmBALD homologs were achieved with the snapdragon $B A L D$ as the query sequence. Contrasted with snapdragon, PmBALDs showed low correlation with the emission of benzenoids with the max TPM of 2,296. Finally, 32 candidate genes were angled homologous to $C b B E A T$ hosting the direct step toward benzyl acetate, and 5 PmBEATs genes were found positively expressed with this component.

\section{Identifying DEGs for Cytochrome P450 and SDR Families}

Many genes of the large enzyme families appeared to flaunt their expressions in the transcriptome profiles using MapMan.

P450 proteins were detected notably arising in the blooming stage within a total of 201 cytochrome P450 genes in P. mume. Moreover, two P450 genes were highlighted in the up-regulated DEGs with a fold change of more than 18 . One gene, predicted as cytochrome P450 82D47, was homologous to Cytochrome $\mathrm{P} 450$ 82A4 in Cajanus cajan, of which the TPM ranged from 2,381 to 45,146 ; the other was isoleucine $\mathrm{N}$-monooxygenase 2 (cytochrome P450 79A68), with a TPM ranging from 605 to 20,604 .

The short-chain dehydrogenases/reductases (SDR) family attended many reactions to convert the aldehyde groups, which might participate in the formation of benzyl alcohol. In the genome of $P$. mume, $147 S D R$ related genes with various expression levels were retrieved, and 9 candidate genes were gained, which were highly expressed in the flower. Among these candidate SDRs, three genes increased to the level of 10,000 TPM in the blooming stage, two around a TPM of 10,000, but in other four organs, the TPM of these genes approached zero or remained low. Though one gene was significantly identified in the blooming stage, higher than the former four genes, there still remained around 4,000 TPM in fruits, leaves, roots or stems. The other four genes peaked in the flower with TPMs under 3,300.

\section{Transcription Factors Out of DEGs}

Transcription factors are believed to be essential in controlling many secondary metabolic processes. In our comparative transcriptome studies for the scent formation of Mei flower, we identified 595 TFs (transcriptional regulators included) of 76 TF families classified by PlantTFDB database, representing 7.61\% of all DEGs (Supplementary Table 6). Most TF gathered in MYB family (50, 8.4\%), followed by bHLH (42, 7.05\%), and NAC $(35,5.88 \%)$. Among the flower specifically expressed genes (profile 46), there were 36 TFs (6\% of 595) distributed in 18 TF families, containing MYB-related (6), MYB (6), NAC (3), etc. MYB family was first discovered in the synthesis of flower scent (Figure 8). Phylogenetic analysis illustrated there was one PmMYB1, homologous to the flower-specific PhEOB1 reported in petunia. $P h E O B$ s and $P m M Y B 1$ fell into the same branch together with AtMYB21 and AtMYB24. And in the next branch, PmMYB2 homologous to AtMYB4 was clustered with PhODORANT1. PmMYB3, and PmMYB4 were homologous to the AtMYB123 (TT2). As for the expression, three genes (PmMYB1, PmMYB6, and PmMYB2) assumed high TPMs in the blooming stage. 


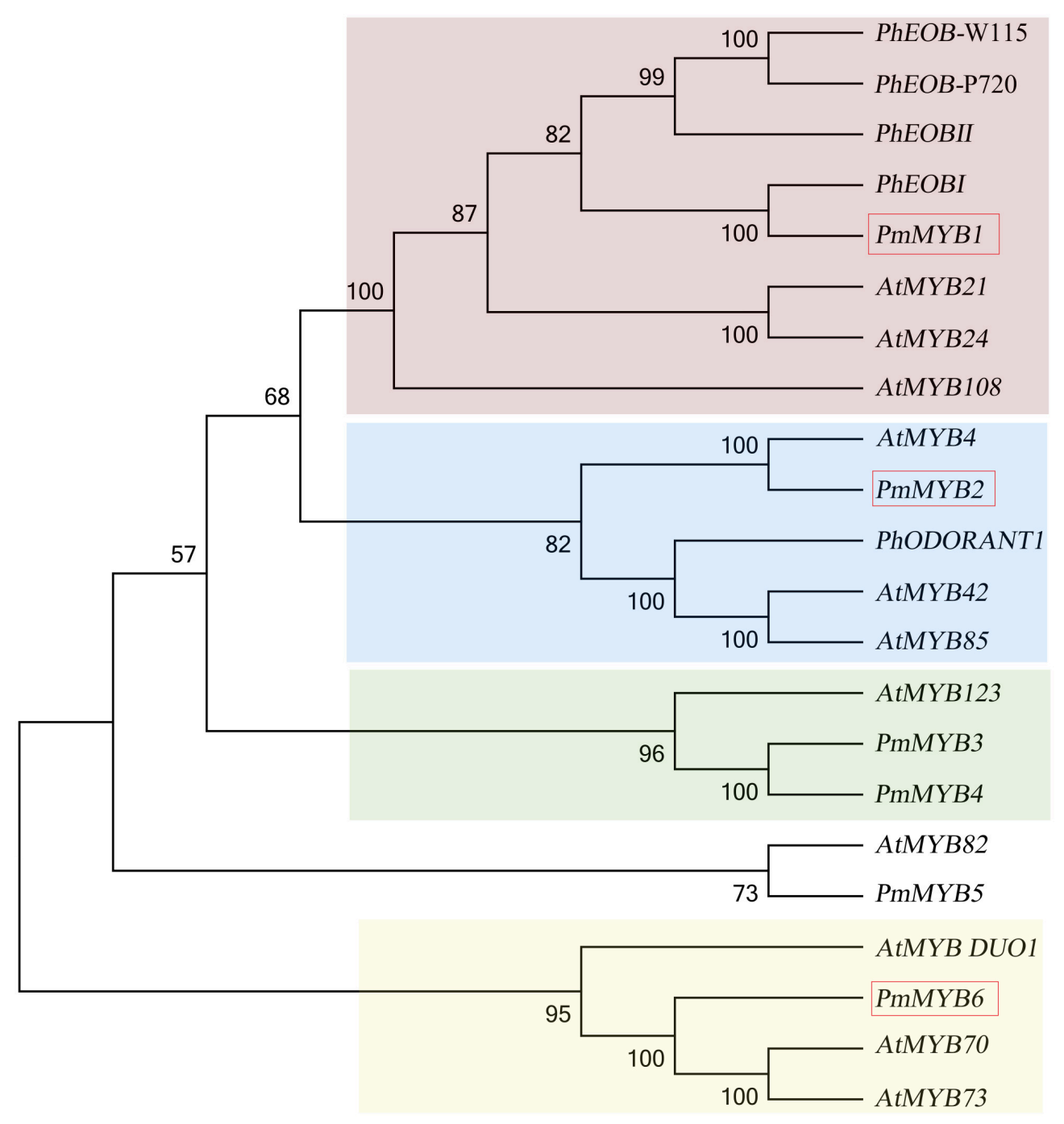

FIGURE 8 | Phylogenetic analysis of MYB transcription factors. TFs in red box mean high expression in blooming stage.

\section{Gene Expression Validation}

A scale of genes related shikimate and benzenoid biosynthesis was selected to test the expression profiles during flower development using real-time quantitative PCR (qRT-PCR) analysis (part results not shown). Sixteen genes in the transcriptome were chosen randomly (Figure 9). The genes expression profiles were primarily coincident with those shown by RNA-seq in tendency and multiplication, though the expression in these genes existed huge difference. The linear regression analysis confirmed the results between q-PCR and RNA-seq and revealed a positive correlation with $\mathrm{R}^{2}$ of 0.54 (Figure 10). These results demonstrated the credibility of sequencing data generated and the pattern profiled in this study.

\section{DISCUSSION}

Mei trees, since their origin in China, have been extensively cultivated in Asia. and an assembled $280 \mathrm{Mb}$ reference genome accelerated the further researches for plant characterization
(Zhang et al., 2012). The previous results indicated that benzenoids were the dominant volatile compounds serving as the core advantage for Prunus species (Hao et al., 2014a). Even though benzenoids are one of the most interesting natural product, the molecular mechanism behind their synthesis is still unknown. Based on 7,813 DEGs achieved from comparative transcriptome analysis, 681 scent-related DEGs specially expressed in flowers were sifted. The mechanism of floral scent formation was gradually explored after the separation of core TFs, specifically the MYB family TFs. These shifty candidate genes offered a bird eye view for the formation of floral fragrance in $P$. mume, thereby constructing a latent network to regulate the structural genes of floral scent. With the scent controlling genes obtained, this transcriptome would lay the basis for revealing biosynthesis pathway of benzenoids, particularly benzyl alcohol and benzaldehyde which acted as the vital precursor substance of principal aroma in Mei flower and was enriched in the species of genus Prunus. 


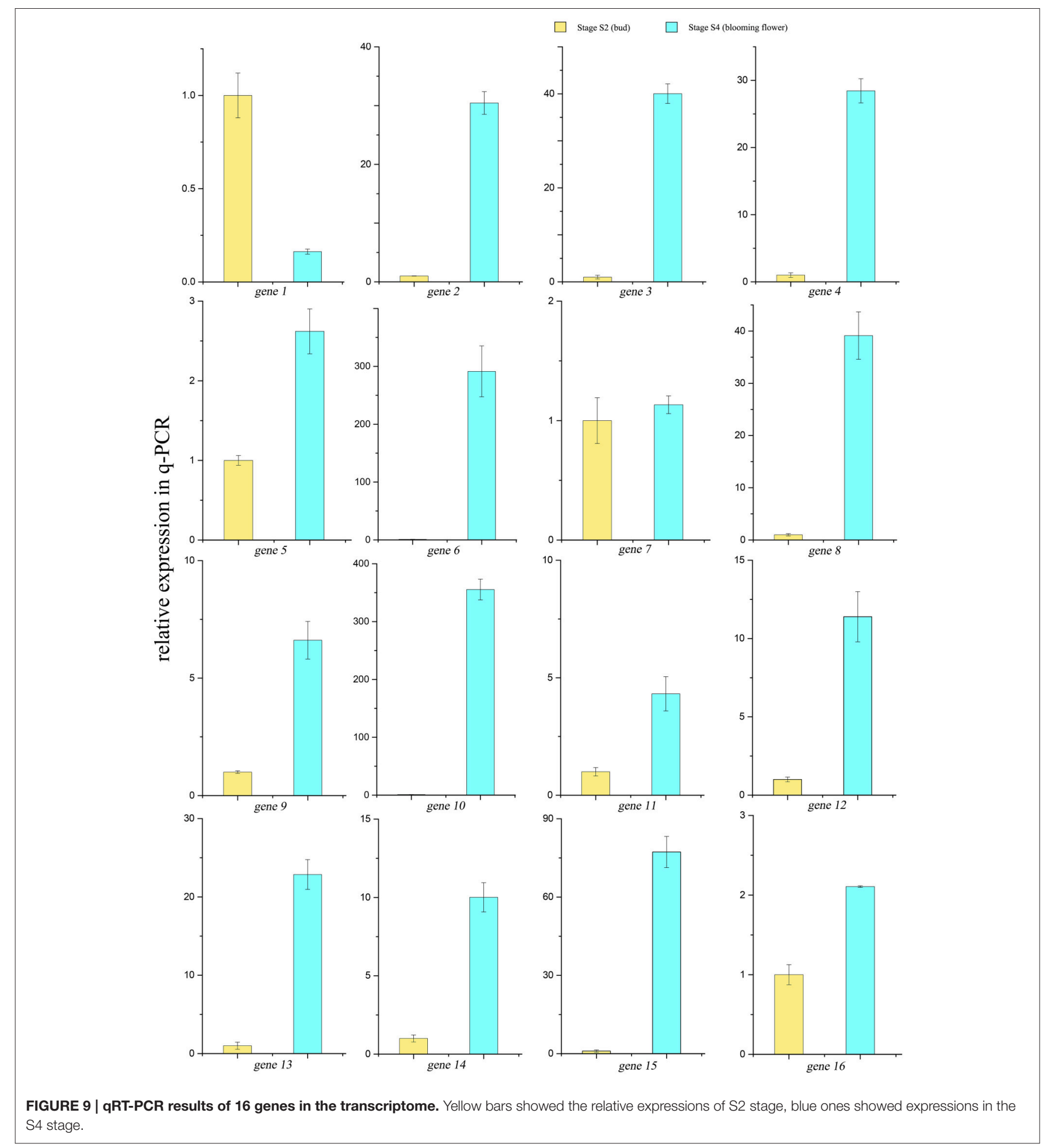

\section{Benzaldehyde Set a Core Anchor in Benzenoids of $P$. mume}

Benzaldehyde is very familiar compound, however, its biosynthesis remains an unresolved issue. Numerous attempts have been made to unmask the truth for a long time, which maybe is the cause of diversification in benzenoids (Croteau, 1978). As for as the scent composition of Mei flower is concerned, benzyl acetate accounted for $90.4 \%$ of the floral volatile compounds, but benzaldehyde possessed $83 \%$ share in the endogenous compositions (Hao et al., 2014b). Indeed, 


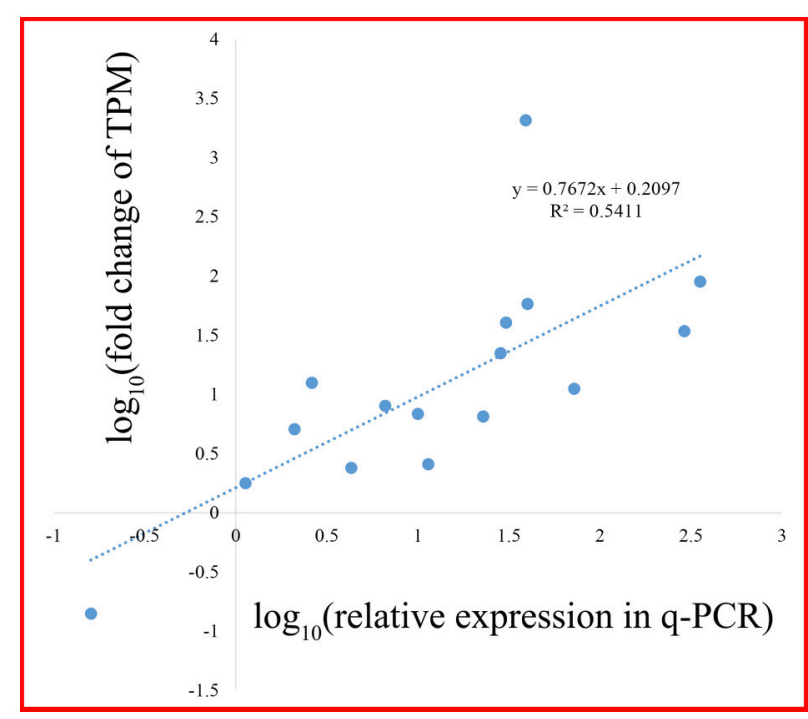

FIGURE 10 | Correlation analysis of fold change between q-PCR and RNA-seq.

the content of benzaldehyde was far larger, almost 7-fold, than that of benzyl acetate. As reported in the petunia and other species, benzaldehyde comes from the phenylalanine by means of isotope labeling (Boatright et al., 2004). Andcinnamoyl-CoA hydratase/ lyase is suspected to catalyze hydration and cleavage of cinnamoyl-CoA to benzaldehyde and acetyl CoA in Hypericum androsaemum (Abd El-Mawla and Beerhues, 2002). CoA ligases seem not to been involved in the production of benzaldehyde in petunia. The suppression of $P h 4 C L$ does not affect the benzenoid spectrum, and there are no changes in benzaldehyde but the components related to BA undergo changes after the RNA interference suppression of PhCNL (Klempien et al., 2012). However, the results of transcriptome in $P$. mume displayed that the expressions of PmPALs and PmCNL were significantly detected in the benzaldehyde production stage, suggesting that the formation of endogenous benzaldehyde might have converged from two paths in the flower of P. mume.

\section{Cytochrome P450 Family Expressed Spatially to form Benzaldehyde}

With up to $1 \%$ of total gene annotations of each plant species, plant cytochrome P450s catalyze plentiful monooxygenation/ hydroxylation reactions in primary and secondary metabolism (Mizutani and Ohta, 2010). In P. mume, two P450s are reported to coexpress to produce the cyanogenic glycosides prunasin and amygdalin (MAN), which originated from phenylalanine (Yamaguchi et al., 2014). CYP79D16 is responsible for the conversion of phenylalanine into phenylacetaldoxime (PAOx) particularly in seedlings. CYP79A68 existed in the buds with the similar structure and was up-regulated in the comparative transcriptome. This drove us to suspect that those two may be controlled to get different functions in different organs. CYP71AN24 has broad substrate specificity, mainly converting PAOx into MAN. After the degradation of MAN, benzaldehyde is released. As a whole in benzenoid pathway, P450s might cleave a new path to the benzaldehyde.

\section{SDR Family May Count for the Benzyl Alcohol}

The SDR genes participate in many aspects of primary and secondary metabolism and are noteworthy in carbonyl-alcohol oxido-reduction (Tonfack et al., 2011). These genes possess at least two domains binding NAD and substrates, respectively, and the latter domain determines the specificity of substrate (Moummou et al., 2012). During the transformation of the phenylalanine, SDR family plays a vital role in the benzenoid volatiles. In the flowers of Damask roses, 2-Phenylethanol (2PE) is biosynthesized from phenylalanine via intermediate phenylacetaldehyde under the catalysis of $P A R$, which is classified as short-chain dehydrogenase reductase (Chen et al., 2011). The presence of highly expressed PmSDRs homologous to PAR satisfied the requirement of benzyl alcohol. And the benzaldehyde was predicted to be transformed via the same oxido-reductive method as the formation of $2 \mathrm{PE}$. The deep research of SDR family may contribute to unravel the accumulation of benzaldehyde in the Prunus.

\section{Heterologous Regulation of the Benzenoid Biosynthesis in Woody Plant}

To date, only a few TFs have been identified in plants to answer the formation of floral scent. There are four MYB members in petunia to regulate benzenoid volatiles (Muhlemann et al., 2014). PhODO1 was the first transcription factor found to promote benzenoid biosynthesis at the stage of scent formation in petunia (Verdonk et al., 2005). This TF functions in the shikimate pathway toward benzenoids by accelerating the core structure enzymes like DHAPS, EPSPS, and PAL. Then, two PhEOBs are found to control the downstream benzenoids, not affecting the color formation (Spitzer-Rimon et al., 2010). Together with these three TFs, a complex feedback loop has been demonstrated to contain positive and negative effects. In $P$. mume, several gateway genes aroused exceedingly, such as PmDAHPSs, PmADTs, and PmPALs, implying the similar regulation method in scent production with petunia. However, there is one ODO-like genes and one EOB-like gene up-regulated in the comparative transcriptome and the kind of structure genes are not all the same as what appears in petunia. These features might distinguish $P$. mume from petunia for scent production no matter in quantity of volatiles or in aroma types. Despite the high expression structure genes and flower specificity, there appears considerable difference in scent regulation for this woody plant.

\section{CONCLUSIONS}

In comparative transcriptome, vital differences of gene expression between bud stage and squaring stage were observed, DEGs with transcriptomes of different organs were found, which provided a special view of floral scent formation in P. mume. Moreover, RNA-seq was helpful to discover the latent scentrelated genes in this dicot. Among them, flower-specific $\mathrm{P} 450$ 
genes and PmSDRs might function in the prime steps controlling the flux into some key precusors like benzaldehyde and benzyl alcohol. All TFs in the DEGs were discerned and classified. Therefore, PmMYBs might master the biosynthesis of the floral volatile benzenoids together some unknown TFs.

All these results furnish practical information to explore the induction for floral scent formation and regulation in $P$. mume. Meanwhile, it also offers us the chance in directional manipulation of volatile spectrum in Prunus to enhance human friendly living condition or commercial values for fruit production. Perhaps the more interesting questions arising from this research are the identification of exact genes contributing to the specification of benzaldehyde and benzyl alcohol, and how those genes are regulated by the TFs. In-depth studies are required to answer these questions and to provide an insight into the regulatory network and induction mechanism of scent woody plants.

\section{AUTHOR CONTRIBUTIONS}

$\mathrm{KZ}$ and WY contributed equally to this work. KZ, WY, and QZ designed the whole experiments. $\mathrm{KZ}$ wrote the manuscript. $\mathrm{KZ}$, YZ, YL, JZ, and SA analyzed the data. All authors read and approved the final manuscript.

\section{REFERENCES}

Abd El-Mawla, A. M., and Beerhues, L. (2002). Benzoic acid biosynthesis in cell cultures of Hypericum androsaemum. Planta 214, 727-733. doi: $10.1007 / \mathrm{s} 004250100657$

Audic, S., and Claverie, J. M. (1997). The significance of digital gene expression profiles. Genome Res. 7, 986-995.

Bar-Akiva, A., Ovadia, R., Rogachev, I., Bar-Or, C., Bar, E., Freiman, Z., et al. (2010). Metabolic networking in Brunfelsia calycina petals after flower opening. J. Exp. Bot. 61, 1393-1403. doi: 10.1093/jxb/erq008

Boatright, J., Negre, F., Chen, X., Kish, C. M., Wood, B., Peel, G., et al. (2004). Understanding in vivo benzenoid metabolism in petunia petal tissue. Plant Physiol. 135, 1993-2011. doi: 10.1104/pp.104.045468

Chandran, A. K., Lee, G. S., Yoo, Y. H., Yoon, U. H., Ahn, B. O., Yun, D. W., et al. (2016). Functional classification of rice flanking sequence tagged genes using MapMan terms and global understanding on metabolic and regulatory pathways affected by dxr mutant having defects in light response. Rice (N Y). 9, 17. doi: 10.1186/s12284-016-0089-2

Chen, J. (1996). Chinese Mei Flowers. Haikou: Hainan Publishing House.

Chen, X. M., Kobayashi, H., Sakai, M., Hirata, H., Asai, T., Ohnishi, T., et al. (2011). Functional characterization of rose phenylacetaldehyde reductase (PAR), an enzyme involved in the biosynthesis of the scent compound 2-phenylethanol. J. Plant Physiol. 168, 88-95. doi: 10.1016/j.jplph.2010.06.011

Croteau, R. (1978). Biosynthesis of benzaldehyde, benzyl alcohol and benzyl benzoate from benzoic acid in cranberry (Vaccinium macrocarpon). J. Food Biochem. 1, 317-326. doi: 10.1111/j.1745-4514.1978.tb00190.x

Dudareva, N., and Pichersky, E. (2008). Metabolic engineering of plant volatiles. Curr. Opin. Biotechnol. 19, 181-189. doi: 10.1016/j.copbio.2008.02.011

Ernst, J., and Bar-Joseph, Z. (2006). STEM: a tool for the analysis of short time series gene expression data. BMC Bioinformatics 7:191. doi: 10.1186/1471-2105-7-191

Fenske, M. P., Hewett Hazelton, K. D., Hempton, A. K., Shim, J. S., Yamamoto, B. M., Riffell, J. A., et al. (2015). Circadian clock gene LATE elongated hypocotyl directly regulates the timing of floral scent emission in Petunia. Proc. Natl. Acad. Sci. U.S.A. 112, 9775-9780. doi: 10.1073/pnas.14228 75112

\section{ACKNOWLEDGMENTS}

The research was supported by National Natural Science Foundation of China (Grant No.31471906), Special Fund for Beijing Common Construction Project, and Specialized Research Fund for the Doctoral Program of Higher Education (20120014120025).

\section{SUPPLEMENTARY MATERIAL}

The Supplementary Material for this article can be found online at: http://journal.frontiersin.org/article/10.3389/fpls.2017. 00319/full\#supplementary-material

\section{Supplementary Figure 1 | Quality score from Fast QC.}

Supplementary Figure 2 | Scatter plot of different expression genes.

Supplementary Figure 3 | DEGs annotation by mercator.

Supplementary Table 1 | Primer sequences for qRT-PCR.

Supplementary Table 2 | The candidate genes in the benzenoid pathway.

Supplementary Table 3 | The up-regulated genes of DEGs in Mei flower.

Supplementary Table 4 | The down-regulated genes of DEGs in Mei flower.

Supplementary Table 5 | GO enrichment analysis of DEGs.

Supplementary Table 6 | TF list in the DEGs.

Finn, R. D., Clements, J., Arndt, W., Miller, B. L., Wheeler, T. J., Schreiber, F., et al. (2015). HMMER web server: 2015 update. Nucleic Acids Res. 43, W30-W38. doi: 10.1093/nar/gkv397

Hao, R., Du, D., Wang, T., Yang, W., Wang, J., and Zhang, Q. (2014a). A comparative analysis of characteristic floral scent compounds in Prunus mume and related species. Biosci. Biotechnol. Biochem. 78, 1640-1647. doi: 10.1080/09168451.2014.936346

Hao, R. J., Zhang, Q., Yang, W. R., Wang, J., Cheng, T. R., Pan, H. T., et al. (2014b). Emitted and endogenous floral scent compounds of Prunus mume and hybrids. Biochem. Syst. Ecol. 54, 23-30. doi: 10.1016/j.bse.2013.12.007

Hurgobin, B. (2016). Short read alignment using SOAP2. Methods Mol. Biol. 1374, 241-252. doi: 10.1007/978-1-4939-3167-5_13

Jin, J., Kim, M. J., Dhandapani, S., Tjhang, J. G., Yin, J. L., Wong, L., et al. (2015). The floral transcriptome of ylang ylang (Cananga odorata var. fruticosa) uncovers biosynthetic pathways for volatile organic compounds and a multifunctional and novel sesquiterpene synthase. J. Exp. Bot. 66, 3959-3975. doi: $10.1093 / \mathrm{jxb} / \mathrm{erv} 196$

Klempien, A., Kaminaga, Y., Qualley, A., Nagegowda, D. A., Widhalm, J. R., Orlova, I., et al. (2012). Contribution of CoA ligases to benzenoid biosynthesis in petunia flowers. Plant Cell 24, 2015-2030. doi: 10.1105/tpc.112.097519

Klie, S., and Nikoloski, Z. (2012). The choice between mapman and gene ontology for automated gene function prediction in plant science. Front. Genet. 3:115. doi: $10.3389 /$ fgene.2012.00115

Knudsen, J. T., Eriksson, R., Gershenzon, J., and Stahl, B. (2006). Diversity and distribution of floral scent. Bot. Rev. 72, 1-120. doi: 10.1663/00068101(2006)72[1:DADOFS]2.0.CO

Li, B., and Dewey, C. N. (2011). RSEM: accurate transcript quantification from RNA-Seq data with or without a reference genome. BMC Bioinformatics 12:323. doi: 10.1186/1471-2105-12-323

Liu, D., Sui, S., Ma, J., Li, Z., Guo, Y., Luo, D., et al. (2014). Transcriptomic analysis of flower development in wintersweet (Chimonanthus praecox). PLoS ONE 9:e86976. doi: 10.1371/journal.pone.0086976

Liu, H., Sun, M., Du, D., Pan, H., Cheng, T., Wang, J., et al. (2015). Wholetranscriptome analysis of differentially expressed genes in the vegetative buds, floral buds and buds of Chrysanthemum morifolium. PLoS ONE 10:e0128009. doi: 10.1371/journal.pone.0128009 
Mariani, T. J., Budhraja, V., Mecham, B. H., Gu, C. C., Watson, M. A., and Sadovsky, Y. (2003). A variable fold change threshold determines significance for expression microarrays. FASEB J. 17, 321-323. doi: 10.1096/fj.02-0351fje

Mizutani, M., and Ohta, D. (2010). Diversification of P450 genes during land plant evolution. Annu. Rev. Plant Biol. 61, 291-315. doi: 10.1146/annurev-arplant-042809-112305

Moummou, H., Kallberg, Y., Tonfack, L. B., Persson, B., and van der Rest, B. (2012). The Plant Short-Chain Dehydrogenase (SDR) superfamily: genome-wide inventory and diversification patterns. BMC Plant Biol. 12:219. doi: 10.1186/1471-2229-12-219

Muhlemann, J. K., Klempien, A., and Dudareva, N. (2014). Floral volatiles: from biosynthesis to function. Plant Cell Environ. 37, 1936-1949. doi: 10.1111 pce.12314

Nam, K. H., Dudareva, N., and Pichersky, E. (1999). Characterization of benzylalcohol acetyltransferases in scented and non-scented Clarkia species. Plant Cell Physiol. 40, 916-923. doi: 10.1093/oxfordjournals.pcp.a029623

Onda, Y., Mochida, K., Yoshida, T., Sakurai, T., Seymour, R. S., Umekawa, Y., et al. (2015). Transcriptome analysis of thermogenic Arum concinnatum reveals the molecular components of floral scent production. Sci. Rep. 5:8753. doi: 10.1038/srep08753

Pichersky, E., and Dudareva, N. (2007). Scent engineering: toward the goal of controlling how flowers smell. Trends Biotechnol. 25, 105-110. doi: 10.1016/j.tibtech.2007.01.002

Qualley, A. V., Widhalm, J. R., Funmilayo, A., Kish, C. M., and Natalia, D. (2012). Completion of the core $\beta$-oxidative pathway of benzoic acid biosynthesis in plants. Proc. Natl. Acad. Sci. U.S.A. 109, 16383-16388. doi: 10.1073/pnas.1211001109

Raguso, R. A. (2008). Wake up and smell the roses: the ecology and evolution of floral scent. Ann. Rev. Ecol. Evol. Syst. 39, 549-569. doi: 10.1146/annurev.ecolsys.38.091206.095601

Ramsak, Ž., Baebler, Š., Rotter, A., Korbar, M., Mozetic, I., Usadel, B., et al. (2014). GoMapMan: integration, consolidation and visualization of plant gene annotations within the MapMan ontology. Nucleic Acids Res. 42(Database issue), D1167-D1175. doi: 10.1093/nar/gkt1056

Spitzer-Rimon, B., Marhevka, E., Barkai, O., Marton, I., Edelbaum, O., Masci, T., et al. (2010). EOBII, a gene encoding a flower-specific regulator of phenylpropanoid volatiles' biosynthesis in petunia. Plant Cell 22, 1961-1976. doi: 10.1105/tpc.109.067280

Sun, L., Yang, W., Zhang, Q., Cheng, T., Pan, H., Xu, Z., et al. (2013). Genome-wide characterization and linkage mapping of simple sequence repeats in mei (Prunus mume Sieb. et Zucc.). PLoS ONE 8:e59562. doi: 10.1371/journal.pone.0059562

Tonfack, L. B., Moummou, H., Latché, A., Youmbi, E., Benichou, M., Pech, J. C., et al. (2011). The plant SDR superfamily: involvement in primary and secondary metabolism. Curr.Top. Plant Biol. 12, 41-53.

Tzin, V., and Galili, G. (2010). New insights into the shikimate and aromatic amino acids biosynthesis pathways in plants. Mol. Plant 3, 956-972. doi: $10.1093 / \mathrm{mp} / \mathrm{ssq} 048$

Van Moerkercke, A., Haring, M. A., and Schuurink, R. C. (2011). The transcription factor emission of benzenoids II activates the MYB ODORANT1 promoter at a MYB binding site specific for fragrant petunias. Plant J. 67, 917-928. doi: 10.1111/j.1365-313X.2011.04644.x

Verdonk, J. C., Haring, M. A., van Tunen, A. J., and Schuurink, R. C. (2005). ODORANT1 regulates fragrance biosynthesis in petunia flowers. Plant Cell 17, 1612-1624. doi: 10.1105/tpc.104.028837

Wang, T., Hao, R., Pan, H., Cheng, T., and Zhang, Q. (2014). Selection of suitable reference genes for quantitative real-time polymerase chain reaction in Prunus mume during flowering stages and under different abiotic stress conditions. J. Am. Soc. Hortic. Sci. Am. Soc. Hortic. Sci. 139, 113-122.

Xu, Z., Zhang, Q., Sun, L., Du, D., Cheng, T., Pan, H., et al. (2014). Genomewide identification, characterisation and expression analysis of the MADSbox gene family in Prunus mume. Mol. Genet. Genomics 289, 903-920. doi: 10.1007/s00438-014-0863-z

Yamaguchi, T., Yamamoto, K., and Asano, Y. (2014). Identification and characterization of CYP79D16 and CYP71AN24 catalyzing the first and second steps in L-phenylalanine-derived cyanogenic glycoside biosynthesis in the Japanese apricot, Prunus mume Sieb. et Zucc. Plant Mol. Biol. 86, 215-223. doi: 10.1007/s11103-014-0225-6

Zhang, J., Zhang, Q., Cheng, T., Yang, W., Pan, H., Zhong, J., et al. (2015). High-density genetic map construction and identification of a locus controlling weeping trait in an ornamental woody plant (Prunus mume Sieb. et Zucc). DNA Res. 22, 183-191. doi: 10.1093/dnares/dsv003

Zhang, Q., Chen, W., Sun, L., Zhao, F., Huang, B., Yang, W., et al. (2012). The genome of Prunus mume. Nat. Commun. 3, 1318. doi: 10.1038/ncomms2290

Zhang, X., and Liu, C. J. (2015). Multifaceted regulations of gateway enzyme phenylalanine ammonia-lyase in the biosynthesis of phenylpropanoids. Mol. Plant 8, 17-27. doi: 10.1016/j.molp.2014.11.001

Zheng, J., Hu, Z., Guan, X., Dou, D., Bai, G., Wang, Y., et al. (2015). Transcriptome analysis of Syringa oblata Lindl. Inflorescence identifies genes associated with pigment biosynthesis and scent metabolism. PLOS ONE 10:e0142542. doi: 10.1371/journal.pone.0142542

Zheng, Y., Jiao, C., Sun, H., Rosli, H. G., Pombo, M. A., Zhang, P., et al. (2016). iTAK: a program for genome-wide prediction and classification of plant transcription factors, transcriptional regulators, and protein kinases. Mol. Plant. 9, 1667-1670. doi: 10.1016/j.molp.2016.09.014

Zhou, Y., Xu, Z., Zhao, K., Yang, W., Cheng, T., Wang, J., et al. (2016). Genomewide identification, characterization and expression analysis of the TCP gene family in Prunus mume. Front. Plant Sci. 7:1301. doi: 10.3389/fpls.2016.01301

Conflict of Interest Statement: The authors declare that the research was conducted in the absence of any commercial or financial relationships that could be construed as a potential conflict of interest.

Copyright (c) 2017 Zhao, Yang, Zhou, Zhang, Li, Ahmad and Zhang. This is an open-access article distributed under the terms of the Creative Commons Attribution License (CC BY). The use, distribution or reproduction in other forums is permitted, provided the original author(s) or licensor are credited and that the original publication in this journal is cited, in accordance with accepted academic practice. No use, distribution or reproduction is permitted which does not comply with these terms. 